\title{
BMJ Open Retrospective analysis of infection and antimicrobial resistance patterns of Mycoplasma genitalium among pregnant women in the southwestern USA
}

Irene A Stafford (1) , ${ }^{1}$ Kelsey Hummel, ${ }^{2}$ James J Dunn, ${ }^{2}$ Kenneth Muldrew, ${ }^{2}$ Alexandra Berra, ${ }^{3}$ Elizabeth Skye Kravitz (D) , ${ }^{4}$ Soumya Gogia (D) , ${ }^{4}$ Irene Martin, ${ }^{5}$ Erik Munson ${ }^{6}$

To cite: Stafford IA, Hummel K, Dunn JJ, et al. Retrospective analysis of infection and antimicrobial resistance patterns of Mycoplasma genitalium among pregnant women in the southwestern USA. BMJ Open 2021;11:e050475. doi:10.1136/ bmjopen-2021-050475

- Prepublication history for this paper is available online. To view these files, please visit the journal online (http://dx.doi org/10.1136/bmjopen-2021050475).

Received 24 February 2021 Accepted 07 May 2021
Check for updates

(C) Author(s) (or their employer(s)) 2021. Re-use permitted under CC BY-NC. No commercial re-use. See rights and permissions. Published by BMJ.

For numbered affiliations see end of article.

Correspondence to Dr Irene A Stafford; irene.stafford@uth.tmc.edu

\section{ABSTRACT}

Background Mycoplasma genitalium is a sexually transmitted infection (STI) pathogen. There have been no published studies concerning symptomatology, prevalence data, antibiotic resistance profiling or reports of co-infection with other STI in pregnant women.

Objective To describe these characteristics among pregnant women attending prenatal clinics in a large tertiary care centre.

Design Remnant genital samples collected from pregnant women between August 2018 and November 2019 were tested for M. genitalium and Trichomonas vaginalis by the transcription-mediated amplification technique. Specimens with detectable M. genitalium RNA were sequenced for 23S rRNA mutations associated with azithromycin resistance and parC and gyrA mutations associated with resistance to moxifloxacin. Demographic, obstetric and STI co-infection data were recorded.

Results Of the 719 samples, 41 (5.7\%) were positive for $M$. genitalium. M. genitalium infection was associated with black race, Hispanic ethnicity and young age $(p=0.003, p=0.008$ and $p=0.004$, respectively). M. genitalium infection was also associated with $T$. vaginalis co-infection and Streptococcus agalactiae (group B Streptococcus) colonisation ( $\mathrm{p} \leq 0.001$ and $p=0.002$, respectively). Of the 41 positive samples, 26 (63.4\%) underwent successful sequencing. Eight (30.8\%) had 23S rRNA mutations related to azithromycin resistance. One of 26 (3.8\%) positive samples with sequencing results had the gyrA gene mutation and 1 of 18 sequenced samples (5.6\%) had the parC gene mutation associated with moxifloxacin resistance.

Conclusions Prevalence rates of $M$. genitalium in pregnant women was $5.7 \%$. M. genitalium infection disproportionately affects young black women co-infected with $T$. vaginalis. Pregnant women remain at risk for persistent infection with M. genitalium due to decreased azithromycin susceptibility.

\section{INTRODUCTION}

Mycoplasma genitalium is an emerging cause of sexually transmitted disease in women. ${ }^{1-10}$ Due to its fastidious nature, culture technique
Strengths and limitations of this study

- This analysis is one of the largest evaluating prevalence rates of Mycoplasma genitalium in pregnant women presenting for routine care.

- M. genitalium infection rates were evaluated across race, age and other demographic and obstetrical variables, including co-infections with other sexually transmitted infections.

- Antibiotic resistance patterns were determined among isolates collected from pregnant patients presenting for routine care.

- Perinatal outcome data were not recorded.

- Prospective data regarding persistent infection were not collected in this analysis.

methods have not proven to successfully identify organism in the clinical environment. ${ }^{1-8}$ Fortunately, with the recent developments of highly sensitive molecular platforms, $M$. genitalium can expeditiously be detected in urogenital samples with $>97 \%$ sensitivity. ${ }^{11-20}$ As a result, contemporary studies have demonstrated this organism to extend beyond the role as a causative agent for non-gonococcal urethritis among men and has now been implicated in female genital tract pathology, including infectious sequelae similar to Chlamydia trachomatis, such as cervicitis, pelvic inflammatory disease and preterm birth. ${ }^{521-32}$

To date, six studies have assessed the role of $M$. genitalium with pregnancy-related complications, including a 2015 meta-analysis $(\mathrm{N}=3128)$ in which $M$. genitalium was found to be significantly associated with an increased risk of preterm birth prior to 37 weeks (pooled $\mathrm{OR}=1.89$ ), with an even higher ratio when other sexually transmitted infection (STI) were accounted for (pooled $\mathrm{OR}=2.3) .{ }^{21-27}$ 
The meta-analysis by Lis $e t a l^{27}$ demonstrated the limitations of prior published data mainly related to varying prevalence rates ranging from $2 \%$ to $20 \%$ in women, with scant data concerning rates of infection among pregnant women. ${ }^{4-7}$ 20-32 Characteristics of $M$. genitalium infection, including antibiotic susceptibility patterns and co-infection rates with other STI agents, have not been evaluated in pregnant women presenting for care. ${ }^{21-32}$ The objective of this study was to determine these characteristics among a cohort of pregnant women in a large tertiary obstetrical care centre.

\section{Design}

After institutional review board's approval from the Baylor College of Medicine, all remnant Aptima Multitest clinician-collected endocervical samples from pregnant women presenting to care between 30 August 2018 and 30 November 2019 were placed in the Aptima swab specimen transport tube, stored for up to 30 days and shipped monthly by overnight mail to Marquette University, Milwaukee, Winconsin, USA, for M. genitalium 16S rRNA and Trichomonas vaginalis testing by the transcriptionmediated amplification technique using Panther System automation (Hologic, San Diego, California, USA) as previously described. ${ }^{11-20}$ Only one sample collected at intake to care was used for each patient presenting obstetrical care and received testing with the Aptima swab for Neisseria gonorrhoeae and C. trachomatis per institutional protocol and guidelines.

M. genitalium positive specimens were shipped to the National Microbiology Laboratory, Public Health Agency of Canada, for additional testing. DNA was extracted from the specimens using the MagNA Pure DNA and Viral Nucleic Acid kit (Roche, Laval) per manufacturer's instruction. Specimens with detectable M. genitalium DNA were subsequently analysed by sequencing the $23 \mathrm{~S}$ rRNA gene to identify mutations associated with azithromycin resistance and parC and gyrA genes associated with resistance to moxifloxacin. ${ }^{20} 28-32$

Demographic variables, obstetrical data, pelvic symptoms consistent with cervicitis (pelvic pressure, vaginal discharge and lower abdominal cramping) and STI co-infection ( $N$. gonorrhoeae, C. trachomatis, herpes simplex virus, HIV, T. vaginalis and human papillomavirus (types 16 and 18)) were collected. Bacterial vaginosis and group B Streptococcus (GBS) colonisation data were extracted from the chart and recorded by the investigators. Patient characteristics, co-infection with other STI and M. genitalium resistance profiles were summarised by means with SD, or frequencies with percentages. Fisher's exact test or the Wilcoxon rank sum test was used to determine differences between women positive and negative for M. genitalium in demographic, clinical characteristics and co-infections with other STIs. Exact 95\% CIs were determined for the resistance profiles. Strengthening the Reporting of Observational Studies in Epidemiology guidelines were followed for the study design, methods and analysis. ${ }^{33}$ All protected health information was removed from discarded samples prior to shipment and all data were entered into a de-identified database using only study numbers to link information at completion of study. Patient consent was not obtained, as this project was a retrospective chart review study involving otherwise discarded samples.

\section{Patient and public involvement}

Patients or the public were not involved in the design, or conduct, or reporting, or dissemination plans of our research. We used de-identified database involving otherwise discarded samples and chart review. There was no patient involved for this study.

\section{RESULTS}

During the study period, 726 remnant samples were collected from all pregnant women from the obstetric clinics at Baylor College of Medicine that underwent routine STI testing at intake to care. Seven samples were inadequate, leaving 719 samples available for M. genitalium testing. Of these, $41(5.7 \%)$ were positive. The majority of women in the study group were Hispanic, $\mathrm{n}=535(74.7 \%)$, and $\mathrm{n}=72.8 \%$ were multiparous. There were no significant differences in gestational or pregestational diabetes, hypertensive disorders in pregnancy and illicit substance use between infected and non-infected women. The demographic and obstetric variables of the study group according to $M$. genitalium infection status are demonstrated in table 1 . The mean age of women infected with $M$. genitalium was younger than non-infected women (24.9 years vs 28.1 years, respectively; $\mathrm{p}=0.004$ ) and $M$. genitalium was significantly associated with black race $(\mathrm{p}=0.003)$ and Hispanic ethnicity $(\mathrm{p}=0.008)$ (table 2$)$. At the time of sample collection, $12.1 \%(85 / 701)$ reported pelvic complaints (pelvic pain, vaginal discharge or lower abdominal cramping). Seven women with positive results for infection with $M$. genitalium were symptomatic (18\%) compared with 78 women who tested negative for M. genitalium infection $(11.8 \%$; $\mathrm{p}=0.307)$.

Table 3 demonstrates the association between M. genitalium and co-infection with other STI. M. genitalium infection was significantly associated with women co-infected with T. vaginalis ( $\mathrm{p} \leq 0.001$ ). In addition, the rate of GBS colonisation was significantly higher among women infected with $M$. genitalium compared with women who tested negative ( $58.3 \%$ vs $16.1 \%$, respectively; $\mathrm{p}=0.002$ ).

Of the samples with detectable $M$. genitalium RNA, 26 $(63.4 \%)$ were of sufficient quantity to undergo conclusive sequencing analysis for azithromycin resistance. Of these, 8/26 (30.7\%) were found to have 23S rRNA mutations (A2059G) associated with azithromycin resistance. Of the 18 samples that were of sufficient quantity to undergo sequencing analysis for the $\operatorname{par} C$ gene mutation, one $(5.6 \%)$ was found to have the $\operatorname{parC}$ (Ser $\rightarrow$ Asn83) gene mutation. Of the 26 samples that were of sufficient quantity to undergo sequencing analysis for the gyrA gene mutation, one $(3.8 \%)$ was found to have that gene 


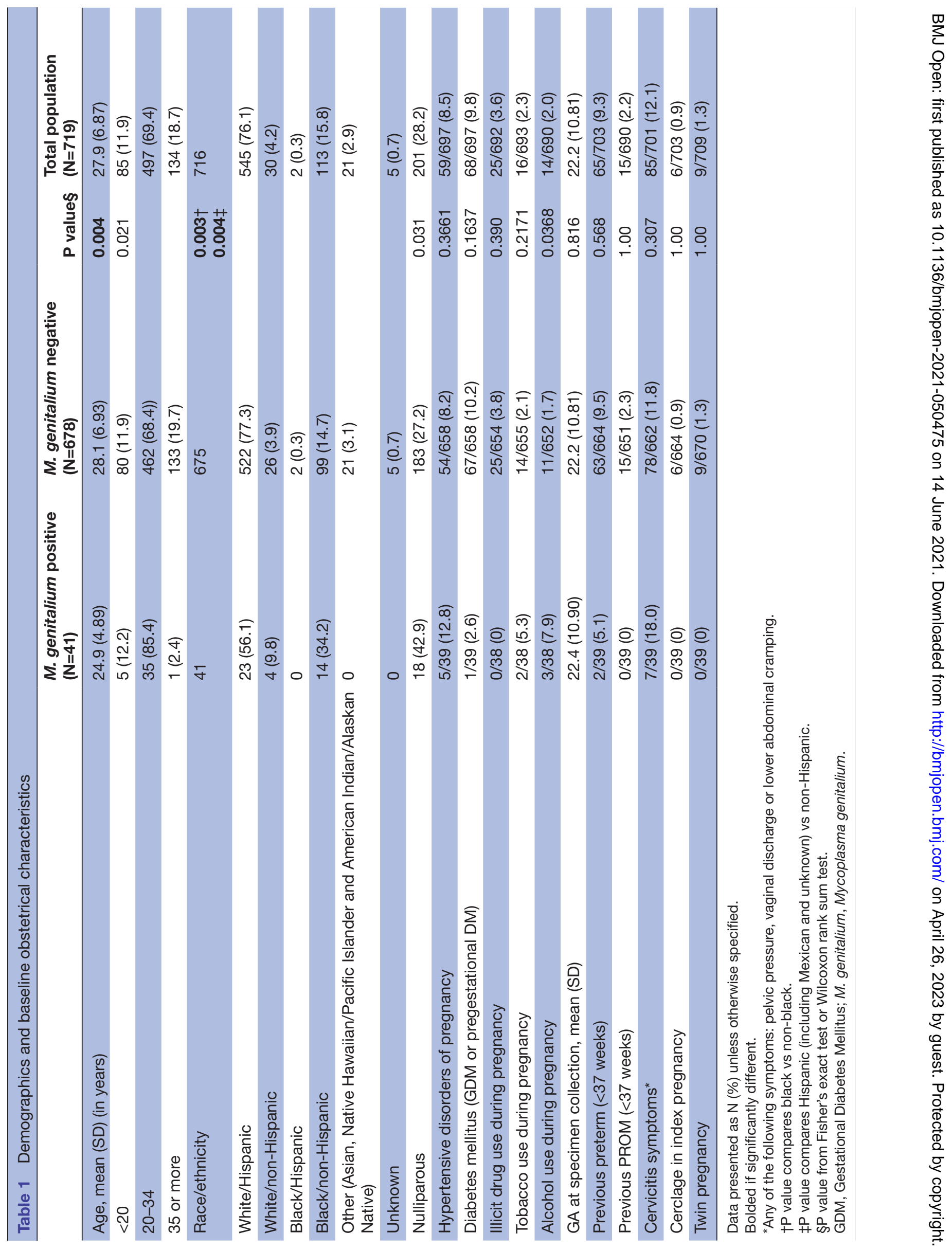


Table 2 Mycoplasma genitalium RNA detection rates from genital swab collections by race/ethnicity

\section{Detection of M. genitalium RNA (n/N1 (\% of subjects))}

\begin{tabular}{ll}
\hline Race/ethnicity & \\
\hline White/Hispanic & $23 / 545(4.2)$ \\
\hline White/non-Hispanic & $4 / 30(13.3)$ \\
\hline Black/Hispanic & $0 / 2(0)$ \\
\hline $\begin{array}{l}\text { Black/non-Hispanic } \\
\text { Other (Asian, Native Hawaiian/Pacific } \\
\text { Islander and American Indian/Alaskan }\end{array}$ & $14 / 113(12.4)$ \\
$\quad$ Native) & $0 / 21(0)$ \\
\hline Race, p value & 0.003 \\
\hline $\begin{array}{l}\text { Black } \\
\text { Non-black }\end{array}$ & $14 / 115(12.2)$ \\
\hline Ethnicity, p value & $27 / 601(4.5)$ \\
\hline Hispanic & 0.008 \\
\hline Non-Hispanic & $23 / 535(4.3)$ \\
\hline
\end{tabular}

$P$ value from Fisher's exact test.

$\mathrm{N} 1=$ number of women tested for the infection with a non-missing value

mutation. Both parC and gyrA gene mutations are associated with moxifloxacin resistance. Sequencing results of all samples are demonstrated in table 4 .

\section{DISCUSSION}

Prevalence rates of $M$. genitalium in this large cohort of pregnant women approximate rates reported in nonpregnant women at 5.7\%. ${ }^{4-7}$ 20-32 Infection with M. genitalium was more prevalent among women at risk for other STI, including black race, young age and co-infection with T. vaginalis $(\mathrm{p}<0.05$ for all). Although macrolide resistance patterns from isolates collected form nonpregnant patients approach 50\%, azithromycin resistance was detected in $30 \%$ of isolates collected from the cohort and $5.6 \%$ demonstrated moxifloxacin resistance. ${ }^{28-32} 34-40$

As described in prior studies, infection with M. genitalium was found to be more prevalent among pregnant women compared with $N$. gonorrhoeae, where reported prevalence rates in women remain less than 1\%. ${ }^{2-1020-323740}$ The adverse health impacts of the more common STI, including N. gonorrhoeae, syphilis, C. trachomatis and herpes simplex virus, on pregnant women are well understood. ${ }^{2-10}$ These have been studied for decades and standard screening and treatment protocols are practiced nationwide with the support of evidence-based guidelines and recommendations for clinical management. ${ }^{10}$ A comparable body of evidence is not available for $M$. genitalium, largely because this organism is relatively understudied as a cause of female genital tract infectious morbidity. ${ }^{679} \mathrm{~A}$ contributing factor to this paradox is that researchers have been unable to apply many of the same culture-based mechanisms and point-of-care testing often used for the diagnosis of other STI towards detection of M. genitalium. ${ }^{11-20}$

With the advent of molecular-based technologies used in research protocols evaluating associations of M. genitalium with adverse reproductive outcomes, this organism has been associated with premature birth, premature rupture of membranes, spontaneous abortion, cervicitis and infertility, implicating this organism as a pathogen in pregnant as well as non-pregnant women. ${ }^{11-19}{ }_{21-32}$ Further understanding of this infection as it relates to pregnancy and adverse perinatal outcomes begins with understanding its characteristics as an STI, and its association with obstetrical factors, demographics, co-infection patterns and pelvic symptomatology as described in our analysis.

\section{Table 3 Co-infections with Mycoplasma genitalium}

\begin{tabular}{lllll}
\hline & $\begin{array}{l}\text { M. genitalium positive } \\
\text { (N=41) } \mathbf{n} / \mathbf{N 1} \text { (\%) }\end{array}$ & $\begin{array}{l}\text { M. genitalium negative } \\
(\mathbf{N = 6 7 8 ) ~ n / N 1 ~ ( \% ) ~}\end{array}$ & P value & $\begin{array}{l}\text { Total population } \\
\text { (N=719) }\end{array}$ \\
\hline $\begin{array}{l}\text { Human papillomavirus, } \\
\text { types 16 and 18 }\end{array}$ & $4 / 14(28.6)$ & $43 / 281(15.3)$ & 0.251 & $47 / 295(15.9)$ \\
\hline Bacterial vaginosis & $5 / 18(27.8)$ & $98 / 340(28.8)$ & 1.000 & $103 / 255(28.8)$ \\
\hline Trichomonas vaginalis & $7 / 40(17.5)$ & $18 / 677(2.7)$ & $<0.001$ & $25 / 717(3.5)$ \\
\hline Chlamydia trachomatis & $6 / 39(15.4)$ & $54 / 670(8.1)$ & 0.131 & $60 / 709(8.5)$ \\
\hline Neisseria gonorrhoeae & $0 / 39(0)$ & $7 / 670(1.0)$ & 1.000 & $7 / 709(1.0)$ \\
\hline Hepatitis B & $0 / 39(0)$ & $2 / 637(0.3)$ & 1.000 & $2 / 676(0.3)$ \\
\hline Hepatitis C & $0 / 17(0)$ & $1 / 281(0.4)$ & 1.000 & $1 / 298(0.3)$ \\
\hline Syphilis & $1 / 37(2.7)$ & $8 / 639(1.3)$ & 0.399 & $9 / 676(1.3)$ \\
\hline Herpes simplex virus 1/2 & $3 / 6(50.0)$ & $23 / 104(22.1)$ & 0.143 & $26 / 110(23.6)$ \\
Group B Streptococcus & $7 / 12(58.3)$ & $40 / 248(16.1)$ & 0.002 & $47 / 260(18.1)$ \\
\hline
\end{tabular}

$\mathrm{N} 1=$ number of women tested for the infection with a non-missing value. $\mathrm{P}$ value from Fisher's exact test. 
Table 4 Prevalence of Mycoplasma genitalium and resistance profiles

\begin{tabular}{|c|c|c|}
\hline & Total $(\mathrm{N}=726)$ & $95 \% \mathrm{Cl}$ \\
\hline $\mathrm{N}$ with sample tested & 719 & \\
\hline M. genitalium positive & $41(5.7)$ & 4.0 to $7.4 \S$ \\
\hline$A 2058 G^{*}$ & $3(7.3)$ & 1.5 to 19.9 \\
\hline $\mathrm{A}_{2058 \mathrm{~T}^{*}}$ & $2(4.9)$ & 0.6 to 16.5 \\
\hline No sequence* & $15(36.6)$ & 22.1 to 53.1 \\
\hline $\mathrm{WT}^{*}$ & $18(43.9)$ & 28.5 to 60.3 \\
\hline Mutation related to azithromycin resistance $†$ & $8 / 26(30.8)$ & 14.3 to 51.8 \\
\hline \multicolumn{3}{|l|}{ GyrA } \\
\hline 95MET(ATG) $\rightarrow$ ILE(ATC)* & $1(2.4)$ & 0.06 to 12.9 \\
\hline $\mathrm{WT}^{*}$ & $25(60.9)$ & 49.4 to 79.9 \\
\hline GyrA mutation † & $1 / 26(3.8)$ & 0.09 to 18.4 \\
\hline \multicolumn{3}{|l|}{ ParC } \\
\hline 83SER(AGT) $\rightarrow$ ILE(ATT)* & $1(2.4)$ & 0.06 to 12.9 \\
\hline 83SER(AGT) $\rightarrow$ ASN(AAT) ${ }^{\star}$ & 0 & 0 to 8.6 \\
\hline Inconclusive ${ }^{*}$ & $9(22.0)$ & 10.6 to 37.6 \\
\hline No sequence* & $14(34.2)$ & 20.1 to 50.6 \\
\hline WT‡ & 17 (41.5) & 26.3 to 57.9 \\
\hline ParC mutation† & $1 / 18(5.6)$ & 0.14 to 27.3 \\
\hline
\end{tabular}

Data presented as $\mathrm{N}(\%)$.

${ }^{*}$ Per cent of positive for M. genitalium.

†Denominator is positive samples with conclusive sequencing results.

$\ddagger$ Wild type.

§Exact 95\% Cls except for which are based on the normal approximation.

A unique finding of this study relates to antimicrobial susceptibility profiles of $M$. genitalium isolated from this pregnant cohort. Although detection rates of macrolide resistance determinants approach $30 \%$ in our population, published rates of macrolide resistance approach $50 \%$ in isolates collected from men. ${ }^{21-32} 3438$ In some countries, strains of multidrug-resistant $M$. genitalium strains exist, limiting therapeutic options. ${ }^{21-32} 3438$ Although the predicted azithromycin resistance is significantly less in this population compared with prior published reports involving men and women, pregnant women remain at significant risk for persistent antenatal infection due to decreased azithromycin susceptibility. The number of cases $(n=2)$ identified with predicted moxifloxacin resistance in this study was low, but it is of concern as extended dose moxifloxacin is currently one of the few alternative options for treatment of macrolide-resistant $M$. genitalium strains, an option not available to pregnant women due to potential fetal teratogenicity and the assigned pregnancy classification. ${ }^{10}$ 35-38

Pristinamycin, an antimicrobial agent synthesised from macrolide and depsipeptide components, has demonstrated promising results as a second-line treatment option with a $75 \%$ cure rate of $M$. genitalium in preliminary studies. ${ }^{38}$ Although not significantly different from moxifloxacin in treatment efficacy among non-pregnant people, pristinamycin remains a potential option during pregnancy and in other situations where fluoroquinolones have failed or are contraindicated. ${ }^{38}$

Data on which to determine whether prenatal treatment of $M$. genitalium can reduce the incidence of pelvic complaints, preterm birth or any other adverse perinatal outcome are still lacking. Future research is warranted to examine relationships between Mycoplasmas and pregnancy, given that some of these organisms may be mechanistically related in their ability to induce inflammatory 
cytokines, potentially leading to preterm labour. ${ }^{11-19}$ 21-27 This gap in knowledge is a significant impediment for implicating this organism as a notifiable cause of reproductive tract disease, and for evidence-based improvement of the current prenatal STI screening and treatment guidelines.

The limitations of our study include the lack of perinatal outcome correlates and a low representation of other STI. The number required to determine meaningful perinatal outcome data, that is, preterm birth, after adjusting for prior preterm birth, using a conservative OR of 1.3 per Lis et al, would require over 17000 patients to determine a $30 \%$ difference in this outcome, even when using higher published prevalence rates among women of $15 \%$ and a macrolide resistance rate of 25\%..$^{21-32} 39$ The information provided in this manuscript can inform research scientists for future prospective studies, including a large, randomised-controlled treatment trial to prevent preterm birth related to M. genitalium infection.

Of note, the co-infection rate of $T$. vaginalis with $M$. genitalium was significant, as was the association of this infection with demographic risk factors common among women with other STI, such as young age and black race. ${ }^{1-1020213940}$ An additional interesting result is the significantly higher association of GBS colonisation in women infected with M. genitalium, a relationship worthy of further investigation. Sample processing was an additional limitation to the study, as samples were shipped across multiple sites, subjecting the samples to preprocessing degradation. Only $68 \%$ of samples contained sufficient material for sequencing for conclusive antibiotic resistance profiling. As these samples were remnant samples that had undergone testing for $N$. gonorrhoeae and C. trachomatis prior to M. genitalium testing, the potential for a reduction in sample quantity was not unexpected, contributing to lower yields. Further prospective studies involving sample collection for $M$. genitalium testing either alone or simultaneously with other STI detected by the Panther transcription-mediated amplification method would result in higher concentrations of genetic material for sequencing analysis.

\section{CONCLUSION}

Our analysis demonstrates that the prevalence of M. genitalium is $5.7 \%$ among a large cohort of pregnant women attending prenatal care in an urban academic centre. $M$. genitalium shares features of other STI, including common demographic risk factors, such as black race and young age. Of the samples with detectable $M$. genitalium RNA that underwent sequencing, $30 \%$ were found to have mutations for resistance to azithromycin. If future studies demonstrate a relationship between $M$. genitalium and adverse perinatal outcomes, alternative therapeutic regimens based on antibiotic susceptibility profiles will need to be determined for the pregnant patient harbouring this STI.

\section{Author affiliations}

${ }^{1}$ Department of Obstetrics and Gynecology, The University of Texas Health Science Center at Houston, Houston, Texas, USA

${ }^{2}$ Department of Pathology and Immunology, Baylor College of Medicine, Houston, Texas, USA

${ }^{3}$ Department of Obstetrics and Gynecology, Baylor College of Medicine, Houston, Texas, USA

${ }^{4}$ Baylor College of Medicine, Houston, Texas, USA

${ }^{5}$ Public Health Agency of Canada, Ottawa, Ontario, Canada

${ }^{6}$ Clinical Laboratory Science, Marquette University, Milwaukee, Wisconsin, USA

Contributors All authors were responsible for data entry which was reviewed by the lead author and validated. IAS, KH, JJD, KM, AB, ESK, BS, SG, IM and EM: all contributed to the data collection, data analysis, protocol development and manuscript preparation. IAS: the guarantor for the overall content.

Funding The authors have not declared a specific grant for this research from any funding agency in the public, commercial or not-for-profit sectors.

Competing interests None declared.

Patient and public involvement Patients and/or the public were not involved in the design, or conduct, or reporting, or dissemination plans of this research.

Patient consent for publication Not required.

Ethics approval This study was approved by the institutional review board and research review committee at the Baylor College of Medicine and Harris Health systems (approval number: H-1809-2029, renewed: 14 July 2020).

Provenance and peer review Not commissioned; externally peer reviewed.

Data availability statement Data are available in a public, open access repository. Data are available upon reasonable request. Extra data can be accessed via the Dryad data repository at http://datadryad.org/ with the doi: 10.5061/dryad. qrfj6q5fq.

Open access This is an open access article distributed in accordance with the Creative Commons Attribution Non Commercial (CC BY-NC 4.0) license, which permits others to distribute, remix, adapt, build upon this work non-commercially, and license their derivative works on different terms, provided the original work is properly cited, appropriate credit is given, any changes made indicated, and the use is non-commercial. See: http://creativecommons.org/licenses/by-nc/4.0/.

\section{ORCID iDs}

Irene A Stafford http://orcid.org/0000-0002-2803-7329

Elizabeth Skye Kravitz http://orcid.org/0000-0002-6003-4451

Soumya Gogia http://orcid.org/0000-0002-0073-8959

\section{REFERENCES}

1 Manhart LE, Holmes KK, Hughes JP, et al. Mycoplasma genitalium among young adults in the United States: an emerging sexually transmitted infection. Am J Public Health 2007;97:1118-25.

2 McGowin CL, Anderson-Smits C. Mycoplasma genitalium: an emerging cause of sexually transmitted disease in women. PLOS Pathog 2011;7:e1001-324.

3 Seña AC, Lee JY, Schwebke J, et al. A silent epidemic: the prevalence, incidence and persistence of Mycoplasma genitalium among young, asymptomatic high-risk women in the United States. Clin Infect Dis 2018;67:73-79.

4 Leli C, Mencacci A, Latino MA, et al. Prevalence of cervical colonization by Ureaplasma parvum, Ureaplasma urealyticum, Mycoplasma hominis and Mycoplasma genitalium in childbearing age women by a commercially available multiplex real-time PCR: An Italian observational multicentre study. J Microbiol Immunol Infect 2018;51:220-225.

5 Anagrius C, Loré B, Jensen JS. Mycoplasma genitalium: prevalence, clinical significance, and transmission. Sex Transm Infect 2005;81:458-62.

6 Wiesenfeld HC, Manhart LE. Mycoplasma genitalium in Women: Current Knowledge and Research Priorities for This Recently Emerged Pathogen. J Infect Dis 2017;216:S389-95.

7 Martin DH. Mycoplasma genitalium from basic science to public health implications: results of a national institute of allergy and infectious diseases technical consultation. J Infect Dis 2017;216:S381. 
8 McGowin CL, Totten PA. The unique microbiology and molecular pathogenesis of Mycoplasma genitalium. J Infect Dis 2017;216:S382-8.

9 Manhart LE, Broad JM, Golden MR. Mycoplasma genitalium: should we treat and how? Clin Infect Dis 2011;53 Suppl 3:S129-42.

10 Centers for Disease Control and Prevention. Sexually transmitted diseases treatment guidelines and STD surveillance data 2018 https://www.cdc.gov/std/stats18/default.htm - last accessed 06/07/21

11 Gaydos CA. Mycoplasma genitalium: accurate diagnosis is necessary for adequate treatment. J Infect Dis 2017;216:S406-11.

12 Yoshida T, Maeda SI, Deguchi T. Rapid detection of Mycoplasma genitalium Mycoplasma hominis, Ureaplasma parvum and Ureaplasma urealyticum. J Clin Microbiol 2003;41:1850.

13 Munson E, Bykowski H, Munson KL, et al. Clinical laboratory assessment of Mycoplasma genitalium transcription-mediated amplification using primary female urogenital specimens. $J$ Clin Microbiol 2016;54:432-8.

14 Jensen JS, Uldum SA, Søndergård-Andersen J, et al. Polymerase chain reaction for detection of Mycoplasma genitalium in clinical samples. J Clin Microbiol 1991;29:46-50.

15 Jensen JS. Protocol for the detection of Mycoplasma genitalium by PCR from clinical specimens and subsequent detection of macrolide resistance-mediating mutations in region $\mathrm{V}$ of the 23SrRNA gene. Method Molec Biol 2012;903:129-39.

16 Wroblewski JKH, Manhart LE, Dickey KA, et al. Comparison of transcription-mediated amplification and PCR assay results for various genital specimen types for detection of Mycoplasma genitalium. J Clin Microbiol 2006;44:3306-12.

17 Gaydos CA, Manhart LE, Taylor SN, et al. Molecular testing for Mycoplasma genitalium in the United States: results from the Ames prospective multicenter clinical study. J Clin Microbiol 2019;57:e01125-19.

18 Jensen JS, Björnelius E, Dohn B, et al. Use of TaqMan 5 nuclease real-time PCR for quantitative detection of Mycoplasma genitalium DNA in males with and without urethritis who were attendees at a sexually transmitted disease clinic. J Clin Microbiol 2004;42:683-92.

19 Hardick J, Giles J, Hardick A, et al. Performance of the gen-probe transcription-mediated [corrected] amplification research assay compared to that of a multitarget real-time PCR for Mycoplasma genitalium detection. J Clin Microbiol 2006;44:1236-40.

20 Getman D, Jiang A, O'Donnell M, et al. Mycoplasma genitalium prevalence, coinfection, and macrolide antibiotic resistance frequency in a multicenter clinical study cohort in the United States. $J$ Clin Microbiol 2016;54:2278-83.

21 Campos GB, Lobão TN, Selis NN, et al. Prevalence of Mycoplasma genitalium and Mycoplasma hominis in urogenital tract of Brazilian women. BMC Infect Dis 2015;15:60.

22 Larsen B, Hwang J. Mycoplasma, Ureaplasma, and adverse pregnancy outcomes: a fresh look. Infect Dis Obstet Gynecol 2010;2010. doi:10.1155/2010/521921. [Epub ahead of print: 1207 2010].

23 Trent M, Coleman JS, Hardick J, et al. Bio-Health study: clinical and sexual risk correlates of Mycoplasma genitalium in urban pregnant and non-pregnant young women. J Pediatr Adolesc Gynecol 2017;30:329-30.

24 Rittenschober-Böhm J, Waldhoer T, Schulz SM, et al. First trimester vaginal Ureaplasma biovar colonization and preterm birth: results of a prospective multicenter study. Neonatology 2018;113:1-6.

25 Averbach SH, Hacker MR, Yiu T, et al. Mycoplasma genitalium and preterm delivery at an urban community health center. Int J Gynaecol Obstet 2013;123:54-7.

26 Donders GGG, Ruban K, Bellen G, et al. Mycoplasma/Ureaplasma infection in pregnancy: to screen or not to screen. J Perinat Med 2017;45:505-15.

27 Lis R, Rowhani-Rahbar A, Manhart LE. Mycoplasma genitalium infection and female reproductive tract disease: a meta-analysis. Clin Infect Dis 2015;61:418-26.

28 Horner P, Ingle SM, Garrett F, et al. Which azithromycin regimen should be used for treating Mycoplasma genitalium? A metaanalysis. Sex Transm Infect 2018;94:14-20.

29 Lau A, Bradshaw CS, Lewis D, et al. The efficacy of azithromycin for the treatment of genital Mycoplasma genitalium: a systematic review and meta-analysis. Clin Infect Dis 2015;61:1389-99.

30 Shimada Y, Deguchi T, Nakane K, et al. Emergence of clinical strains of Mycoplasma genitalium harbouring alterations in ParC associated with fluoroquinolone resistance. Int $J$ Antimicrob Agents 2010;36:255-8.

31 Wikström A, Jensen JS. Mycoplasma genitalium: a common cause of persistent urethritis among men treated with doxycycline. Sex Transm Infect 2006;82:276-9.

32 Hilton J, Azariah S, Reid M. A case-control study of men with nongonococcal urethritis at Auckland sexual health service: rates of detection of Mycoplasma genitalium. Sex Health 2010;7:77-81.

33 Vandenbroucke JP, von Elm E, Altman DG, et al. Strengthening the reporting of observational studies in epidemiology (STROBE): explanation and elaboration. PLoS Med 2007;4:e29.

34 Deguchi T, Yoshida T, Yokoi S, et al. Longitudinal quantitative detection by real-time PCR of Mycoplasma genitalium in first-pass urine of men with recurrent nongonococcal urethritis. J Clin Microbiol 2002;40:3854-6.

35 Friedman JM, Polifka JE. Teratogenic effects of drugs. A resource for clinicians (TERIS. Baltimore, MD: The Johns Hopkins University Press, 2000: 149-95.

36 Czeizel AE, Rockenbauer M. Teratogenic study of doxycycline. Obstet Gynecol 1997;89:524-8.

37 Horne HW, Kundsin RB. The role of Mycoplasma among 81 consecutive pregnancies: a prospective study. Int J Fertil 180;25:315-7.

38 Read TRH, Jensen JS, Fairley CK, et al. Use of pristinamycin for macrolide-resistant Mycoplasma genitalium infection. Emerg Infect Dis 2018;24:328-35.

39 Nye MB, Harris AB, Pherson AJ, et al. Prevalence of Mycoplasma genitalium infection in women with bacterial vaginosis. $B M C$ Womens Health 2020;20:62.

40 Smullin CP, Green H, Peters R, et al. Prevalence and incidence of Mycoplasma genitalium in a cohort of HIV-infected and HIVuninfected pregnant women in Cape Town, South Africa. Sex Transm Infect 2020;96:501-8. 